Editorial

\title{
Emerging Technologies for Harnessing the Fourth Industrial Revolution in the Energy and Mineral Industries
}

\author{
Yosoon Choi $\mathbb{D}$ \\ Department of Energy Resources Engineering, Pukyong National University, Busan 48513, Korea; \\ energy@pknu.ac.kr; Tel.: +82-33-570-6313
}

Received: 26 November 2020; Accepted: 9 December 2020; Published: 15 December 2020

\section{Introduction}

The Fourth Industrial Revolution provides new ways in which technology can become embedded within societies and even the human body. As the Fourth Industrial Revolution accelerates, innovations are becoming faster, more efficient, and more widely accessible than before. Technology is also becoming increasingly interconnected; in particular, emerging technologies such as the Internet of Things (IoT), cloud computing, big data analytics, mobile and wearable devices, augmented and virtual realities (VR), 3D printing, robotics, autonomous vehicles, and artificial intelligence (AI) are emerging in various fields.

These periodic changes also have a significant influence on the energy and mineral industries. The concepts of "smart mining" in the mineral industry and "digital oil field" in the oil and gas industry have established themselves as representative keywords representing the Fourth Industrial Revolution of the industry in the era of digital transformation. Emerging technologies are being introduced/converged throughout the cycle from resource exploration, development, production, processing, and environmental restoration. Additionally, the Revolution affects the paradigm shift of the existing academic system in the energy and mineral industries.

This Special Issue includes seven publications from esteemed research groups worldwide. Research papers in this Special Issue belong to the following broad categories: (1) big data platform and analytics, (2) AI, and (3) VR and wearable devices.

\section{Big Data Platform and Analytics}

In recent times, a massive amount of structured and unstructured data with volumes between 1 terabyte and 1 petabyte, referred to as "big data," are rapidly generated from IoT devices and collected in the cloud platform, and then processed and analyzed using different techniques according to the purposes, for the energy and mineral industries. Wang et al. [1] summarized the current status of China's digital mining platform. The study analyzed the theoretical framework of a mining technology collaboration platform, including the concept, connotation, characteristics, architecture, and related technical requirements. An example of this is the mining technology collaboration platform of the Fujian Makeng Iron Mine, China, that was developed to save time and resources for data collection and further processing.

Baek and Choi [2] provided an example of big data analytics in mining. The study used big data generated by an ICT-based mine safety management system in an underground limestone mine, in South Korea. The data collected over a period of three months, from 1 October to 31 December 2018, were analyzed to calculate the averages and standard deviations of the truck cycle times for ore haulage operations. The results were used as input parameters for the discrete event simulation program to 
predict the haulage times, the number of haulage operations, production output, and truck delay times per day. More reliable simulation results were obtained as data accumulation time was increased.

\section{Artificial Intelligence}

AI technologies such as machine learning are attracting attention to effectively analyze the big data produced, collected, and shared in real time in the energy and mineral industries. Nguyen et al. [3] proposed models of artificial neural networks (ANN) and their ensembles to predict the flight distance of rocks caused by blasting in open-pit mines. The study collected data from 210 fly rock events in open-pit mines and used $80 \%$ of the entire dataset to develop the models and the remaining $20 \%$ to test the developed models. The performance of each machine learning model was evaluated by calculating the mean absolute error (MAE), mean absolute percentage error (MAPE), root-mean-square error (RMSE), correlation coefficient $\left(\mathrm{R}^{2}\right)$, and variance accounted for (VAF). The results showed that the ensemble of ANN models yielded better performance with an MAE $=2.777$, MAPE $=0.017$, RMSE $=4.346, \mathrm{R}^{2}=0.986$, and VAF $=98.446 \%$ compared to that of the ANN models with the same structure.

LV et al. [4] compared seven machine learning techniques, including random forest (RF), ANN, k-nearest neighbors (kNN), cubist, support vector machine (SVM), stochastic gradient boosting (SGB), and classification and regression tree (CART) to predict ilmenite content in beach placers. Of the 405 beach placer borehole samples, 325 samples were used to build the machine learning models, and 80 remaining samples were used in the models. Based on the evaluation criteria calculated by RMSE, $R^{2}$, a simple ranking method, and the residual analysis technique, the study indicated that the SGB model was the most appropriate for determining ilmenite content.

Baek and Choi [5] presented a deep neural network (DNN)-based method for predicting ore production by truck haulage systems in open-pit mines. DNN models were trained using data obtained from an open-pit limestone mine in South Korea over a two-month period and optimized by varying the number of hidden layers and their corresponding nodes. The results showed that the MAPE predictions for morning and afternoon ore production equaled $11.40 \%$ and $8.87 \%$, respectively, and the error between the actual and predicted ore productions on a given day was $4.17 \%$. The DNN-based method could predict ore production by using the data without the help of conventional truck haulage system simulation methods based on complex algorithms.

Han et al. [6] compared supervised machine learning models including RF, gradient boosting tree (GBM), and SVM to predict the productivity of shale gas wells using data from 150 shale gas wells in the Eagle Ford shale gas field, USA. The data contain various parameters, such as hydraulic fracturing and well completion. The 129 shale gas wells for data preprocessing were used as training datasets for supervised learning models. Optimal input variables were selected by using the variable importance method (VIM), and cluster analysis was used to analyze the similarities in the datasets and recreate the machine learning models for each cluster to compare training and test results. The RF with the IncNodePurity-based VIM showed the best prediction performance when compared to other supervised learning models.

\section{Virtual Reality and Wearable Devices}

The VR technology enables users to perceive the virtual world as if it were real and to interact with it by providing a variety of sensations to users in the virtual world implemented using a computer [7]. To apply VR technology to the energy and mineral industries, it is important to develop effective devices to control industry-specific contents in a VR environment. Kim and Choi [8] compared the performance of four devices (2D mouse, 2D and 3D mice, a VR controller, and a Kinect (Microsoft) sensor and wearable bend-sensing data gloves) for controlling mining industry software in a VR environment. The experimental study showed that the 2D mouse yields high performance in terms of its working time; however, it did not completely leverage the VR environment. The Kinect sensor and 
wearable bend-sensing data gloves, in contrast, could control the software efficiently while maximizing user immersion.

Funding: This work was supported by Basic Science Research Program through the National Research Foundation of Korea (NRF) funded by the Ministry of Education (2018R1D1A1A09083947).

Acknowledgments: This Special Issue would not be possible without the contributions of professional authors and reviewers, and the excellent editorial team of Applied Sciences.

Conflicts of Interest: The author declares no conflict of interest.

\section{References}

1. Wang, J.; Bi, L.; Wang, L.; Jia, M.; Mao, D. A Mining Technology Collaboration Platform Theory and Its Product Development and Application to Support China's Digital Mine Construction. Appl. Sci. 2019, 9, 5373. [CrossRef]

2. Baek, J.; Choi, Y. Simulation of Truck Haulage Operations in an Underground Mine Using Big Data from an ICT-Based Mine Safety Management System. Appl. Sci. 2019, 9, 2639. [CrossRef]

3. Nguyen, H.; Bui, X.-N.; Nguyen-Thoi, T.; Ragam, P.; Moayedi, H. Toward a State-of-the-Art of Fly-Rock Prediction Technology in Open-Pit Mines Using EANNs Model. Appl. Sci. 2019, 9, 4554. [CrossRef]

4. LV, Y.; Le, Q.-T.; Bui, H.-B.; Bui, X.-N.; Nguyen, H.; Nguyen-Thoi, T.; Dou, J.; Song, X. A Comparative Study of Different Machine Learning Algorithms in Predicting the Content of Ilmenite in Titanium Placer. Appl. Sci. 2020, 10, 635. [CrossRef]

5. Baek, J.; Choi, Y. Deep Neural Network for Predicting Ore Production by Truck-Haulage Systems in Open-Pit Mines. Appl. Sci. 2020, 10, 1657. [CrossRef]

6. Han, D.; Jung, J.; Kwon, S. Comparative Study on Supervised Learning Models for Productivity Forecasting of Shale Reservoirs Based on a Data-Driven Approach. Appl. Sci. 2020, 10, 1267. [CrossRef]

7. Steuer, J. Defining Virtual Reality: Dimensions Determining Telepresence. J. Commun. 1992, 42, 73-93. [CrossRef]

8. Kim, H.; Choi, Y. Performance Comparison of User Interface Devices for Controlling Mining Software in Virtual Reality Environments. Appl. Sci. 2019, 9, 2584. [CrossRef]

Publisher's Note: MDPI stays neutral with regard to jurisdictional claims in published maps and institutional affiliations.

(C) 2020 by the author. Licensee MDPI, Basel, Switzerland. This article is an open access article distributed under the terms and conditions of the Creative Commons Attribution (CC BY) license (http://creativecommons.org/licenses/by/4.0/). 